\title{
Chinese beliefs in luck are linked to gambling problems via strengthened
} cognitive biases

\author{
Lim, Matthew S. M.; Rogers, Robert D.
}

\section{Journal of Gambling Studies}

DOI:

$10.1007 / \mathrm{s} 10899-017-9690-6$

Published: 01/12/2017

Peer reviewed version

Cyswllt i'r cyhoeddiad / Link to publication

Dyfyniad o'r fersiwn a gyhoeddwyd / Citation for published version (APA):

Lim, M. S. M., \& Rogers, R. D. (2017). Chinese beliefs in luck are linked to gambling problems via strengthened cognitive biases: A mediation test. Journal of Gambling Studies, 33(4), 13251336. https://doi.org/10.1007/s10899-017-9690-6

\footnotetext{
Hawliau Cyffredinol / General rights

Copyright and moral rights for the publications made accessible in the public portal are retained by the authors and/or other copyright owners and it is a condition of accessing publications that users recognise and abide by the legal requirements associated with these rights.

- Users may download and print one copy of any publication from the public portal for the purpose of private study or research.

- You may not further distribute the material or use it for any profit-making activity or commercial gain

- You may freely distribute the URL identifying the publication in the public portal ?
}

Take down policy

If you believe that this document breaches copyright please contact us providing details, and we will remove access to the work immediately and investigate your claim. 


\title{
Chinese beliefs in luck are linked to gambling problems via strengthened cognitive biases: A mediation test
}

\author{
Matthew S.M. Lim ${ }^{1} \&$ Robert D. Rogers ${ }^{2}$ \\ ${ }^{1}$ Department of Psychology, National University of Singapore \\ ${ }^{2}$ School of Psychology, Bangor University \\ Abstract: 160 words \\ Text: 3,308 words \\ Tables: 2 \\ Figures: 1 \\ Address for correspondence: \\ Dr. Matthew Lim \\ Department of Psychology \\ National University of Singapore \\ Block AS4, \#03-13 \\ 9 Arts Link \\ Singapore 117570 \\ Tel: +65 66011189 \\ Email: psymlsm@nus.edu.sg
}

\section{Funding}

This study was completed as part of a doctoral thesis and no external sources of funding were sort.

\section{Contributors}

MSML and RDR designed the study, wrote the protocol and conducted literature searches. MSML organized the data collection and conducted the statistical analysis. MSML and RDR wrote the final manuscript.

\section{Conflict of Interest}

All other authors declare that they have no conflicts of interest relevant to the work presented here.

\section{Ethical approval}

All procedures performed in studies involving human participants were in accordance with the ethical standards of the institutional and/or national research committee and with the 1964 Helsinki declaration and its later amendments or comparable ethical standards. This article does not contain any studies with animals performed by any of the authors. 


\section{Abstract}

Problematic patterns of gambling and their harms are known to have culturally specific expressions. For ethnic Chinese people, patterns of superstitious belief in this community appear to be linked to the elevated rates of gambling-related harms; however, little is known about the mediating psychological mechanisms. To address this issue, we surveyed 333 Chinese gamblers residing internationally and used a mediation analysis to explore how gambling-related cognitive biases, gambling frequency and variety of gambling forms ('scope') mediate the association between beliefs in luck and gambling problems. We found that cognitive biases and scope were significant mediators of this link but that the former is a stronger mediator than the latter. The mediating erroneous beliefs were not specific to any particular type of cognitive bias. These results suggest that Chinese beliefs in luck are expressed as gambling cognitive biases that increase the likelihood of gambling problems, and that biases that promote gambling (and its harms) are best understood within their socio-cultural context.

Keywords: Chinese gambling; beliefs in luck; problem gambling; gambling-related cognitive biases; gambling scope. 


\section{Introduction}

Gambling and its harms are ubiquitous across cultures, but, at the same time, have culturally specific expressions (Raylu and Oei 2004b). For example, the rates of severe gambling problems amongst the Chinese people (up to $4 \%$ Hong Kong and Macao) are higher than the rates found in Caucasian cultures (up to $1.1 \%$ in the UK and the US) (Wardle et al. 2010; D. K. C. Fong and Ozorio 2005; Social Sciences Research Centre 2005; Shaffer et al. 1999). Additionally, within a multicultural Asian country such as Singapore where rates of gambling problems are relatively low $(0.7 \%)$, ethnic Chinese residents report more clinically significant problems with their gambling compared to other ethnic Asians such as the Malays and Indians (reviewed in Winslow et al. 2015). Exploring the sources of these variations can help us understand the susceptibility to gambling problems across and within different cultural groups.

Superstitious beliefs in luck (Darke and Freedman 1997) are also pervasive amongst the Chinese people, and is probably the cultural milieu that heightens and sustains gambling-related harms in this population (Loo et al. 2008). Superstitious beliefs reported amongst ethnic Chinese include the beliefs in the effectiveness of 风水 Ifeng-shuil or geomancy to improve personal luck (Zheng et al. 2010), the use of horoscopes to predict the future, and the belief that certain numbers such as " 6 " and " 8 " have lucky properties because they are homonyms of the Chinese words for "smoothness" and "prosperity" respectively (Huang and Teng 2009).

The psychological construct of luck has been defined in the (Western) literature as both an internal property of a person as well as an external property of situations and environments (Wohl et al. 2011; Darke and Freedman 1997). Luck as an internal and stable property of person is similar to how the Chinese talk about luck in fatalistic terms of one's predestined 命运 /ming-yun/ or 'life-luck' (Papineau 2005). These beliefs probably do not increase Chinese people's susceptibility to cognitive biases about their control within games of chance. However, Chinese conceptions of the external sources of luck may increase such susceptibility. This is because the Chinese view external sources of luck, 运气 /yun-qi/ or 'lucky circumstances', as open to manipulation through culturally sanctioned practices (Pritchard and Smith 2004). Critically, this latter formulation of luck is consistent with the ubiquitous cultural practices of Chinese geomancy (Mak and Ng 2005), and "luck-talk" during Chinese festive occasions (M. Fong 2000) to alter personal fortuity.

Chinese beliefs in luck are associated with gambling problems (Tao et al. 2011; Zheng et al. 2010). However, 
the psychological mediators of this link are not well understood. Gambling-related cognitive biases are significant factors in the development and maintenance of gambling problems (Oei et al. 2007, 2008) and may constitute the crucial psychological mediator of this relationship. Some evidence suggests that the tendency to expect positive effects from gambling (i.e., gambling expectancy biases) mediate the relationship between beliefs in 'fate determinism' and gambling problems in a Chinese sample (Tang and Wu 2010). While fate determinism centres around internal and stable aspects of luck (Papineau 2005), the present study focusses upon beliefs in the external and controllable aspects of luck. One way in which such Chinese conceptions of luck may increase or exacerbate gambling harms is through the promotion of interpretive biases that explain away losses through external unforeseen circumstances or increase perceived control through instrumental superstitious behaviours (i.e., illusions of control) (Raylu and Oei 2004a).

Here, we surveyed an international sample of Chinese people online to test the hypothesis that gamblingspecific cognitive biases and errors positively mediate the association between luck and gambling problems (Hypothesis 1). Other data show that behavioural indicators of gambling intensity (as volume or variety of bets and games per unit time) is positively related to both beliefs in luck (Zhou et al. 2012) and gambling problems (Lloyd et al. 2010). Additionally, the clinical criteria for gambling addiction, as assessed by the Diagnostic and Statistical Manual of Mental Disorders, includes behavioural items such as chasing after losses, gambling more in order to get the same excitement (tolerance) and loss of control over gambling behaviour (American Psychiatric Association 2013). Therefore, we included 'behavioural' indicators of gambling frequency (as volume of gambling per unit time) and gambling scope (as variety of gambling forms) to test against the hypothesised mediating role of cognitive biases. It is hypothesized that gambling frequency and scope are both positive mediators of the luck and disordered gambling association (Hypotheses $2 \mathrm{a}$ and $2 \mathrm{~b}$ respectively). Finally, as there is a strong line of evidence that show cognitive distortions as risk factors for gambling harms (Toneatto et al. 1997; Delfabbro 2004; Ladouceur 2004; Oei et al. 2008), it is hypothesized that cognitive biases will be a stronger mediator of gambling harms compared to the behavioural mediators of gambling frequency and scope (Hypothesis 3). The study found that gambling-related cognitive biases were indeed a stronger mediator than the behavioural indicators measured.

\section{Method}

The study was approved by the Central University Research Ethics Committee of the University of Oxford. All 
participants gave written informed consent.

\section{Participants}

A sample of 611 Chinese participants were recruited between July, 2011, and March, 2012 via hyperlinks on websites hosted in the UK and Singapore with the incentive of a prize draw for an iPad. These websites supported Chinese community forums and were not gambling specific. Websites hosted in the UK and Singapore were selected out of convenience because they were willing to support the survey and had a large number of Chinese subscribers. E-mail advertisements were also sent out by a Hong Kong tabloid newspaper to their international subscribers and a majority of the sample from Hong Kong and Mainland China were recruited through this method (59.8\%). A total of 489 complete responses were obtained ( $80 \%$ completion rate), and of these, 333 (263 males) participants reported gambling at least once in the past year. It is the responses of this subsample of gamblers that were used in the mediation analysis (see Table $\mathbf{1}$ for a description of this sample).

\section{Measures}

The survey was administered in both English and traditional Chinese script depending on the websites where the study was advertised.

Chinese Beliefs in Luck Scale (CBLS). Published questionnaire assessments of luck in previous Chinese studies were unsuitable for use in the study because they did not capture the broad conceptions of luck in diverse gambling and geographical settings (Zheng et al. 2010; Huang and Teng 2009; Hernandez et al. 2008; Tao et al. 2011). For our purposes, items from previous instruments (the Chinese Superstitious Belief Scale, the Superstitious Beliefs Scale, and the Indigenous Inventory Scale) were selected if they assessed prominent content domains of luck found in the literature (M. Fong 2000; Huang and Teng 2009; Hernandez et al. 2008) i.e., beliefs in the use of homonyms in speech, superstitions behaviours, crystals, Chinese geomancy, horoscopes, and charms to promote luck.

A panel of seven Chinese people from a variety of East and Southeast countries (Singapore, China, Hong Kong, Malaysia) then indicated whether the collated items from previous scales were relevant to Chinese people from their own country of origin. This was done using a 'Yes/No' response format (1: Yes $\mid 0$ : No). Only items endorsed by all members of the panel were selected for use in the CBLS. This was done to ensure that every 
item was intelligible to Chinese people living internationally. Eleven items were selected using this process and were translated, and back translated, by two native Chinese speakers; all discrepancies were resolved by consensus (see Table S1 and Table S2).

Table 1 about here

Participants rated questionnaire items on a 7-point Likert scale (1: Strongly disagree |7: Strongly agree). An exploratory factor analysis of the scale using the 489 complete responses revealed a 4 -factor structure in the scale: beliefs in changing luck, lucky wins, lucky numbers, and lucky signs (see Supplementary Materials). The total scores on this scale (Cronbach's $\alpha=.94$ ) demonstrated good internal consistency in this sample.

Gambling-Related Cognitions Scale (GRCS). To assess gambling cognitive biases, we administered the English and Chinese versions of the GRCS (Raylu and Oei 2004a; Oei et al. 2007) which has a 5-factor structure: illusions of control, interpretive biases, gambling expectancies, predictive control, and the perceived inability to stop gambling. Participants rated all statements on a 7-point Likert scale (1: strongly disagree |7: strongly agree). The total (Cronbach's $\alpha=.95$ ) and subscale scores (Cronbach's $\alpha=.80$ to .89 ) showed good internal consistency in this sample.

Gambling frequency and scope. Participants reported how frequently (in the past year) they participated on a list of 16 different gambling activities (e.g., Mah-jong, horse racing, sports betting, and casino play). These were rated on a 4-point scale (0: no gambling | 1: less than once a month $\mid 2$ : one to three times a month |3: weekly). Gambling scope was defined by the summed number of all gambling activities with at least monthly frequency. Gambling frequency was defined by the highest frequency of a single activity, not including lottery or Mah-jong play. These latter forms of gambling were excluded because lottery play $(r=.13)$ and Mah-jong $(r=.06)$ reflected social forms of gambling and were found to have smaller associations with gambling problems in this sample compared to activities such as horse-racing $(r=.29)$, sports betting $(r=.32)$, or casino play $(r=.34)$. Their exclusion ensured that the gambling frequency construct measured risky forms of gambling involvement.

Problem Gambling Severity Index (PGSI). Gambling-related harm was measured using the English and Chinese versions of the PGSI (Loo et al. 2011; Holtgraves 2009). Participants rated statements about their difficulties with gambling on a 4-point scale (0: Never|3: Almost always) and were considered probable problem gamblers if they scored 8 point or above. Total scores on this scale achieved good internal consistency in this sample (Cronbach's $\alpha=.92)$. 


\section{Data Analysis}

\section{Mediation of gambling-related cognitive biases, gambling frequency and gambling scope}

A boot-strapped mediation analysis (Preacher and Hayes 2008) was performed to quantify the relationship between beliefs in luck and gambling problems. Total score on the GRCS, gambling frequency and gambling scope were entered as mediating variables; whilst age, gender (1: male |0: female) and first language (1: any Chinese language | 0 : others) were added as covariates. To facilitate comparisons between mediators by standardised coefficients, all variables were transformed as $z$-scores. To avoid multi-collinear problems, this analysis was repeated separately for the GRCS subscale individually as they were highly correlated $(r=.56$ to .85). All mediation analyses were conducted using a customized syntax for SPSS provided by Preacher and Hayes (2008).

\section{Results}

Fifty-three (15.4\%) of the 333 gamblers were classified as probable problem gamblers on the PGSI. Unsurprisingly, this self-selected sample of gamblers is at higher risk for clinically significant gambling problems (Hwu et al. 1989; Social Sciences Research Centre 2005) and gambling-related cognitive biases (Oei et al. 2007) compared to normative Chinese samples.

\section{Mediation of beliefs in luck on gambling problems}

A correlation matrix of all important variables in the mediation model can be found in Table 2 .

The direct association between Chinese beliefs in luck and the severity of gambling problems was significant $(\beta$ $=.19, t=3.63, p<.001)$. However, this relationship became non-significant once the three mediators of cognitive bias, gambling frequency and gambling scope were added $(\beta=-.05, t=-1.18, p>.05)$. Now, in this form, the total mediation effect was significant $(\beta=.25,95 \% \mathrm{CI}=.18$ to .32 ; see Fig. 1).

Table 2 and Fig 1 about here

As predicted, Chinese gamblers who held stronger beliefs in luck were more likely to report problems with their gambling because they tended to endorse more gambling cognitive biases $(\beta=.20,95 \% \mathrm{CI}=.14$ to .27$)$ and 
participated in a broader range of gambling activities $(\beta=.06,95 \% \mathrm{CI}=.02$ to .11$)$. Gambling frequency was not a significant mediator $(\beta<-.01,95 \% \mathrm{CI}=-.04$ to .01$)$. Planned comparisons showed that the indirect effect of gambling cognitive biases was significantly larger than the indirect effect of gambling scope $(\beta=.14,95 \% \mathrm{CI}$ $=.07$ to .22 ). When the analysis was repeated using each of the subscales of the GRCS, every subscale score similarly mediated beliefs in luck and gambling problems (all $p<.05$; see Fig. S1).

\section{Discussion}

Consistent with previous observations (Joukhador et al. 2004; Chiu and Storm 2010), this study revealed an association between Chinese beliefs in luck and the severity of gambling problems as scored by the PGSI (Loo et al. 2011; Holtgraves 2009). However, our data advance our understanding of this association by demonstrating that a broad range of cognitive biases and the variety of gambling participation both mediate this relationship.

These data show that Chinese beliefs in non-personal sources of luck (as lucky wins, numbers, and signs), that can be used for personal gain, facilitate without specification a wide variety of cognitive biases captured by the GRCS: these biases include individuals' perceived inability to stop gambling, their illusions of control, their expectancy that gambling has mood-enhancing effects, their tendency to attribute losing outcomes to unforeseeable events, and their beliefs that it is possible to predict when gambling games will pay out. These cognitive distortions then mediate the emergence of gambling problems.

These findings complement the previous finding that individuals' gambling expectancy of mood-regulating effects of gambling mediate the association between beliefs in fate (both as internal and personal conceptions of luck) and gambling problems (Tang and Wu 2010). However, unlike these previous findings, our data here demonstrate that external and controllable aspects of luck (CBLS) also increase risk for severe gambling problems, through a broad repertoire of cognitive biases.

These findings advance our understanding of the possible reasons for the higher rates of gambling-related harms reported in the Chinese compared to Caucasians and other non-Chinese Asians (Wardle et al. 2010; D. K. C. Fong and Ozorio 2005; Social Sciences Research Centre 2005; Shaffer et al. 1999; Winslow et al. 2015). Specifically, the linguistic and customary traditions of the Chinese people maintain a luck-oriented worldview (M. Fong 2000; Papineau 2005) that has been shown here to increase risk for clinically significant gambling 
problems. These superstitious beliefs are embedded in customs such as scripted greetings during lunar New Year celebrations to promote the good health and prosperity of family members (M. Fong 2000). They are also seen in the thriving business of Chinese geomancy practices (Mak and $\mathrm{Ng}$ 2005; Chang et al. 2009).

Beliefs in luck probably promote gambling-specific cognitive biases such as illusions of control (Langer 1975) by offering Chinese people a subjective way of retaining indirect control in games of chance where direct control is unavailable (Rothbaum et al. 1982). There is a strong line of evidence that demonstrate how players' active involvement in games of chance (e.g., picking up cards, balls, and dice) is associated to greater appraisals of skill and control, and actual risk-taking compared to players not given these opportunities to participant behaviourally in games (Davis et al. 2000; Strickland et al. 1966; Dunn and Wilson 1990; Martinez et al. 2009; Chau and Phillips 1995; Fernandez-Duque and Wifall 2007). An experimental study also demonstrated that gamblers given the opportunity to apply brakes to slot machine games (e.g. Ladouceur and Sevigny 2005) can induce greater gambling persistence and appraisals of control after play. More striking is the evidence that this illusion of control can work retrospectively. Getting players to perform ritualistic behaviours after losing a lottery (i.e., drawing their feelings of loss on a piece of paper; sprinkling salt on it; then tearing it up and counting to ten), can induce stronger ratings of control independent of whether players believed in rituals or not (Norton and Gino 2013).

These studies suggest that beliefs in luck could promote illusions of control by offering gamblers a larger number of ways to actively participate in games of chance. Over time, the active use of lucky numbers, colours, clothing, charms, and environments (through geomancy), as measured by the CBLS, could be used to 'scaffold' further beliefs in the power of instrumental action to influence game outcomes. This translation of luck beliefs into mistaken gambling cognitions through active involvement could be more common in Chinese people as a population as they are known to have a lower internal (direct) locus of control (Spector et al. 2004), and have stronger beliefs in the use rituals and charms (indirect active control), compared to their Caucasian counterparts (Oei et al. 2008).

Additionally, beliefs in luck could enhance cognitive biases such as predictive control (where gamblers are overconfident of their ability to predict outcomes), or interpretive biases (where they attribute their wins to personal skill and losses to external circumstances) (Raylu and Oei 2004a). Beliefs in luck help gamblers resolve ambiguity or uncertainty in games. This is consistent with previous qualitative data that revealed how Chinese people in Hong Kong and Singapore use superstitious practices of geomancy to make decisions in 
situations of incomplete information, too much information, or a lack of information to differentiation between options (Tsang 2004). Betting in sport, horse and dog racing, and casino table games all creates similar experiences of decisional ambiguity. Therefore it is likely that beliefs in luck help Chinese gamblers resolve ambiguity in non-veridical ways by imbibing certain gambling options with greater meaning (or expected value) (Ng et al. 2010). This may explain why people with stronger beliefs in luck show increased experimentation of new consumer products ("Consumer Nolvelty Seeking"; Hernandez et al. 2008) and, critically, the finding here that Chinese gamblers who belief in luck engage in a larger variety of gambling forms.

Nevertheless, inferences from these results are subject to significant caveats. Firstly, the sample was selfselecting and may not be representative of Chinese gamblers as a population. As such, the generalizability of the results is severely limited. This limitation of non-random sampling, however, was weighed between the benefit of achieving a large enough sample of Chinese gamblers in the community who report gambling problems (reviewed in Wood and Griffiths 2007). This secondary aim was achieved with a large number of regular gamblers classified as 'probable problem gamblers' (15.4\%).

Secondly, the generalizability of the results is further limited by possible systematic differences between those who completed the survey versus those who dropped out midway. These systematic differences were investigated here and it was found that completers of the survey were more likely to live in China/ Hong Kong and Singapore as opposed to the UK $(p<.05)$. Completers also reported more years of gambling $(p<.05)$ compared to non-completers. No differences in gambling-related problems were found between completers and non-completers $(p>.05)$. The self-selecting sample of gamblers here, though not representative of all gamblers in the community, is more likely to represent gamblers with more established patterns of gambling and who live within a largely Chinese cultural context.

Thirdly, the cross-sectional design of the study precludes causal conclusions. Similar to previous cross-sectional studies (Tao et al. 2011; Zheng et al. 2010), the direction of the association between beliefs in luck and gambling harms has never been tested longitudinally. The direction of this relationship could very well be inverted, where gambling problems increase gamblers' attention to luck-related contingencies in the environment as they get more desperate to win. More representative and longitudinal data is thus required to determine the direction, or reciprocity, of this relationship between beliefs in luck and gambling harms. A replication of the model in help-seeking pathological gamblers will also support the proposed role of luck in a clinical context. 
Notwithstanding the above limitations, this study extends previous research by demonstrating that gamblingrelated cognitive biases mediate the link between culturally-contingent beliefs and practices that reference luck and gambling harms (Raylu and Oei 2004b). 


\section{Ethical approval:}

All procedures performed in studies involving human participants were in accordance with the ethical standards of the institutional and/or national research committee and with the 1964 Helsinki declaration and its later amendments or comparable ethical standards. This article does not contain any studies with animals performed by any of the authors. 


\section{References}

American Psychiatric Association (2013). Diagnostic and statistical manual of mental disorders: DSM-5. Washington, DC: American Psychiatric Association.

Chang, P. T., Lee, J. H., Hung, K. C., Tsai, J. T., \& Perng, C. (2009). Applying fuzzy weighted average approach to evaluate office layouts with Feng-Shui consideration. Mathematical and Computer Modelling, 50(9-10), 1514-1537, doi:DOI 10.1016/j.mcm.2008.07.038.

Chau, A. W., \& Phillips, J. G. (1995). Effects of Perceived Control Upon Wagering and Attributions in Computer Blackjack. Journal of General Psychology, 122(3), 253-269.

Chiu, J., \& Storm, L. (2010). Personality, Perceived Luck and Gambling Attitudes as Predictors of Gambling Involvement. Journal of Gambling Studies, 26(2), 205-227, doi:DOI 10.1007/s10899-009-9160-x.

Darke, P. R., \& Freedman, J. L. (1997). The belief in good luck scale. Journal of Research in Personality, 31(4), 486-511, doi:DOI 10.1006/jrpe.1997.2197.

Davis, D., Sundahl, I., \& Lesbo, M. (2000). Illusory Personal Control as a Determinant of Bet Size and Type in Casino Craps Games. Journal of Applied Social Psychology, 30(6), 1224-1242.

Delfabbro, P. (2004). The stubborn logic of regular gamblers: Obstacles and dilemmas in cognitive gambling research. Journal of Gambling Studies, 20(1), 1-21.

Dunn, D. S., \& Wilson, T. D. (1990). When the Stakes Are High - a Limit to the Illusion-of-Control Effect. Social Cognition, 8(3), 305-323.

Fernandez-Duque, D., \& Wifall, T. (2007). Actor/observer asymmetry in risky decision making. Judgment and Decision Making Journal, 2(1), 1-8.

Fong, D. K. C., \& Ozorio, B. (2005). Gambling Participation and Prevalence Estimates of Pathological Gambling in a Far-East Gambling City: Macao. UNLV Gaming Research \& Review Journal, 9(2), 1528.

Fong, M. (2000). 'Luck Talk' in celebrating the Chinese New Year. Journal of Pragmatics, 32(2), 219-237.

Hernandez, M. D., Wang, Y. J., Minor, M. S., \& Liu, Q. (2008). Effects of superstitious beliefs on consumer novelty seeking and independent judgment making: Evidence from China. Journal of Consumer Behaviour, 7, 424-435.

Holtgraves, T. (2009). Evaluating the Problem Gambling Severity Index. Journal of Gambling Studies, 25(1), $105-120$

Huang, L. S., \& Teng, C. I. (2009). Development of a Chinese Superstitious Belief Scale. Psychological Reports, 104(3), 807-819, doi:Doi 10.2466/Pr0.104.3.807-819.

Hwu, H. G., Yeh, E. K., \& Chang, L. Y. (1989). Prevalence of Psychiatric-Disorders in Taiwan Defined by the Chinese Diagnostic Interview Schedule. Acta Psychiatrica Scandinavica, 79(2), 136-147.

Joukhador, J., Blaszczynski, A., \& Maccallum, F. (2004). Superstitious beliefs in gambling among problem and non-problem gamblers: Preliminary data. Journal of Gambling Studies, 20(2), 171-180, doi:Doi 10.1023/B:Jogs.0000022308.27774.2b.

Ladouceur, R. (2004). Perceptions among pathological and nonpathological gamblers. Addictive Behaviors, 29(3), 555-565, doi:DOI 10.1016/j.addbeh.2003.08.025.

Ladouceur, R., \& Sevigny, S. (2005). Structural characteristics of video lotteries: Effects of a stopping device on illusion of control and gambling persistence. Journal of Gambling Studies, 21(2), 117-131, doi:10.1007/s10899-005-3028-5.

Langer, E. J. (1975). The illusion of control. Journal of Personality and Social Psychology, 32(2), 311-328.

Lloyd, J., Doll, H., Hawton, K., Dutton, W. H., Geddes, J. R., Goodwin, G. M., et al. (2010). Internet Gamblers: A Latent Class Analysis of Their Behaviours and Health Experiences. Journal of Gambling Studies, 26(3), 387-399, doi:DOI 10.1007/s10899-010-9188-y.

Loo, J. M., Oei, T. P., \& Raylu, N. (2011). Psychometric evaluation of the problem gambling severity indexchinese version (PGSI-C). Journal of Gambling Studies, 27(3), 453-466.

Loo, J. M., Raylu, N., \& Oei, T. P. S. (2008). Gambling among the Chinese: A comprehensive review. Clinical Psychology Review, 28(7), 1152-1166, doi:DOI 10.1016/j.cpr.2008.04.001.

Mak, M. Y., \& Ng, S. T. (2005). The art and science of Feng Shui - a study on architects' perception. Building and Environment, 40(3), 427-434, doi:DOI 10.1016/j.buildenv.2004.07.016.

Martinez, F., Bonnefon, J.-F., \& Hoskens, J. (2009). Active involvement, not illusory control, increases risk taking in a gambling game. Quarterly Journal of Experimental Psychology, 62(6), 1063-1071.

Ng, T., Chong, T., \& Du, X. (2010). The value of superstitions. Journal of Economic Psychology, 31(3), 293309, doi:DOI 10.1016/j.joep.2009.12.002.

Norton, M. I., \& Gino, F. (2013). Rituals Alleviate Grieving for Loved Ones, Lovers, and Lotteries. Journal of experimental psychology. General, doi:10.1037/a0031772. 
Oei, T. P., Lin, J., \& Raylu, N. (2007). Validation of the chinese version of the gambling related cognitions scale (GRCS-C). Journal of Gambling Studies, 23(3), 309-322, doi:DOI 10.1007/s10899-006-9040-6.

Oei, T. P., Lin, J., \& Raylu, N. (2008). The relationship between gambling cognitions, psychological states, and gambling - A cross-cultural study of Chinese and Caucasians in Australia. Journal of Cross-Cultural Psychology, 39(2), 147-161, doi:Doi 10.1177/0022022107312587.

Papineau, E. (2005). Pathological gambling in Montreal's chinese community: An anthropological perspective. Journal of Gambling Studies, 21(2), 157-178, doi:DOI 10.1007/s10899-005-3030-y.

Preacher, K. J., \& Hayes, A. F. (2008). Asymptotic and resampling strategies for assessing and comparing indirect effects in multiple mediator models. Behavior Research Methods, 40(3), 879-891.

Pritchard, D., \& Smith, M. (2004). The psychology and philosophy of luck. New Ideas in Psychology, 22(1), 128, doi:DOI 10.1016/j.newideapsych.2004.03.001.

Raylu, N., \& Oei, T. P. (2004a). The gambling related cognitions scale (GRCS): Development, confirmatory factor validation and psychometric properties. Addiction, 99(6), 757-769, doi:DOI 10.1111/j.13600443.2004.00753.x.

Raylu, N., \& Oei, T. P. (2004b). Role of culture in gambling and problem gambling. Clinical Psychology Review, 23(8), 1087-1114.

Rothbaum, F., Weisz, J. R., \& Snyder, S. S. (1982). Changing the world and changing the self: A two-process model of perceived control. Journal of Personality and Social Psychology, 42(1), 5-37.

Shaffer, H. J., Hall, M. N., \& Vander Bilt, J. (1999). Estimating the prevalence of disordered gambling behavior in the United States and Canada: A research synthesis. American Journal of Public Health, 89(9), 1369-1376.

Social Sciences Research Centre (2005). A study of Hong Kong people's participation in gambling activities, December, 2005. Hong Kong: Home Affairs Bureau, Government of the Hong Kong Special Administrative Region.

Spector, P. E., Sanchez, J. I., Siu, O. L., Salgado, J., \& Ma, J. (2004). Eastern versus Western control beliefs at work: An investigation of secondary control, socioinstrumental control, and work locus of control in China and the US. Applied Psychology, 53(1), 38-60.

Strickland, L. H., Lewicki, R. J., \& Katz, A. M. (1966). Temporal Orientation and Perceived Control as Determinants of Risk-Taking. Journal of Experimental Social Psychology, 2(2), 143-151, doi:Doi 10.1016/0022-1031(66)90075-8.

Tang, C. S. K., \& Wu, A. M. S. (2010). Direct and Indirect Influences of Fate Control Belief, Gambling Expectancy Bias, and Self-Efficacy on Problem Gambling and Negative Mood Among Chinese College Students: A Multiple Mediation Analysis. Journal of Gambling Studies, 26(4), 533-543, doi:DOI 10.1007/s10899-010-9177-1.

Tao, V. Y. K., Wu, A. M. S., Cheung, S. F., \& Tong, K. K. (2011). Development of an Indigenous Inventory GMAB (Gambling Motives, Attitudes and Behaviors) for Chinese Gamblers: An Exploratory Study. Journal of Gambling Studies, 27(1), 99-133, doi:DOI 10.1007/s10899-010-9191-3.

Toneatto, T., Blitz-Miller, T., Calderwood, K., Dragonetti, R., \& Tsanos, A. (1997). Cognitive distortions in heavy gambling. Journal of Gambling Studies, 13(3), 253-266.

Tsang, E. W. (2004). Superstition and decision-making: Contradiction or complement? The Academy of Management Executive, 18(4), 92-104.

Wardle, H., Moody, A., Spence, S., Orford, J., Volberg, R., Jotangia, D., et al. (2010). British Gambling Prevalence Survey 2010. National Centre for Social Research.

Winslow, M., Cheok, C., \& Subramaniam, M. (2015). Gambling in Singapore: An overview of history, research, treatment and policy. Addiction, 110(9), 1383-1387.

Wohl, M. J. A., Stewart, M. J., \& Young, M. M. (2011). Personal Luck Usage Scale (PLUS): Psychometric validation of a measure of gambling-related belief in luck as a personal possession. International Gambling Studies, 11(1), 7-21.

Wood, R. T., \& Griffiths, M. D. (2007). Online data collection from gamblers: Methodological issues. International Journal of Mental Health and Addiction, 5(2), 151-163.

Zheng, W. Y., Walker, M., \& Blaszczynski, A. (2010). Mahjong Gambling in the Chinese-Australian Community in Sydney: A Prevalence Study. Journal of Gambling Studies, 26(3), 441-454, doi:DOI 10.1007/s10899-009-9159-3.

Zhou, K., Tang, H., Sun, Y., Huang, G. H., Rao, L. L., Liang, Z. Y., et al. (2012). Belief in luck or in skill: Which locks people into gambling? Journal of Gambling Studies, 28(3), 379-391. 
Table 1 Descriptive statistics of 333 gamblers

\begin{tabular}{|c|c|c|c|}
\hline & Mean $(S D)$ & & $N(\%)$ \\
\hline Age (years) & $42.79(15.40)$ & Gender (Males) & $263(79.0 \%)$ \\
\hline Age at first gamble (years) & $18.17(6.34)$ & First language (Chinese) & $250(75.1 \%)$ \\
\hline $\begin{array}{l}\text { Gambling Cognition/ GRCS } \\
\text { Gambling expectancies } \\
\text { Illusions of control } \\
\text { Predictive control } \\
\text { Perceived inability to stop } \\
\text { Interpretive control/bias } \\
\text { Total score }\end{array}$ & $\begin{array}{l}11.84(5.00) \\
10.80(5.48) \\
17.64(7.41) \\
12.26(7.00) \\
13.01(5.76) \\
65.53(26.06)\end{array}$ & $\begin{array}{l}\text { Education level } \\
\text { Primary education and below } \\
\text { Secondary education } \\
\text { Diploma/ A-levels } \\
\text { College or university } \\
\text { Post-graduate degree }\end{array}$ & $\begin{aligned} & 9(2.7 \%) \\
& 134(40.2 \%) \\
& 58(17.4 \%) \\
& 90(27.0 \%) \\
& 42(12.6 \%)\end{aligned}$ \\
\hline & & $\begin{array}{l}\text { Country of residence } \\
\text { China/ Hong Kong } \\
\text { Singapore } \\
\text { United Kingdom } \\
\text { Others }\end{array}$ & $\begin{array}{r}199(59.8 \%) \\
76(22.8 \%) \\
53(15.9 \%) \\
5(1.5 \%)\end{array}$ \\
\hline & & $\begin{array}{l}\text { Gambling scope } \\
2 \text { or less activities } \\
3-4 \text { activities } \\
5 \text { or more activities }\end{array}$ & $\begin{array}{r}258(77.4 \%) \\
45(13.5 \%) \\
30(9.1 \%)\end{array}$ \\
\hline & & $\begin{array}{l}\text { Gambling frequency } \\
\text { Less than once a month } \\
\text { 1-3 times a month } \\
\text { 1-5 times a week } \\
\text { Daily }\end{array}$ & $\begin{array}{r}104(31.2 \%) \\
80(24.0 \%) \\
122(36.6 \%) \\
27(8.1 \%)\end{array}$ \\
\hline & & $\begin{array}{l}\text { Gambling problems/ PGSI } \\
\text { Recreational gamblers } \\
\text { Low-risk gamblers } \\
\text { Moderate-risk gamblers } \\
\text { Probable problem gamblers }\end{array}$ & $\begin{array}{r}94(28.2 \%) \\
82(24.6 \%) \\
105(31.2 \%) \\
53(15.4 \%)\end{array}$ \\
\hline
\end{tabular}

Note. GRCS - Gambling Related Cognitions Scale; PGSI - Past year gambling problems as assessed by the Problem Severity Index; Gambling scope - Number of gambling activities that are played more than one a month; Gambling frequency - Past year gambling on a preferred gambling activity. 
Table 2 Correlation matrix of beliefs in luck, gambling-related cognitive biases, gambling scope, gambling frequency and gambling problems for 333 gamblers

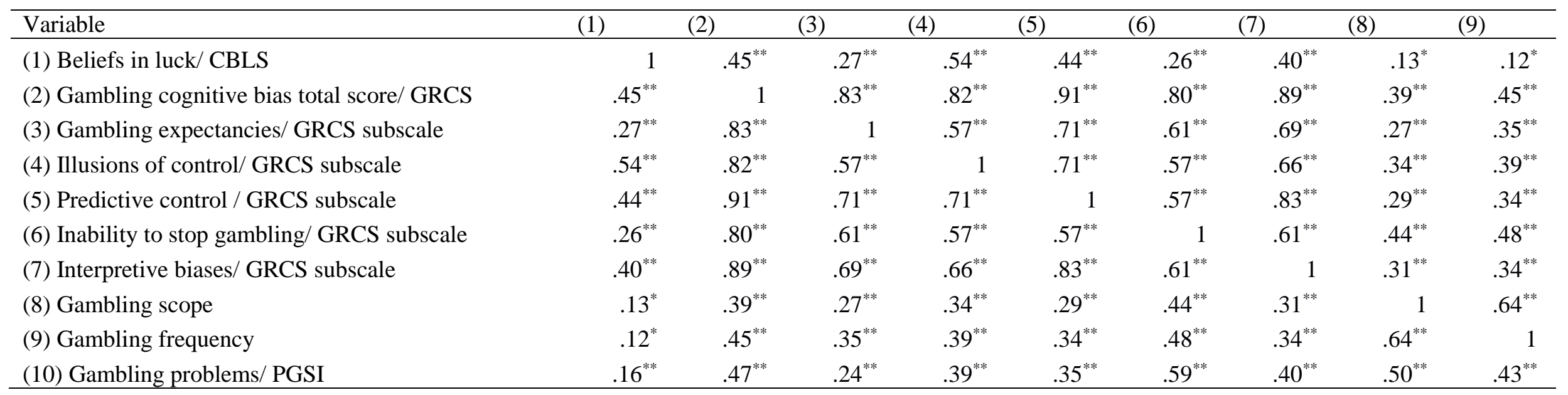

Note. $* r<.05 ; * * r<.01$; CBLS - Chinese Beliefs in Luck Scale; GRCS - Gambling Related Cognitions Scale; Gambling scope - Number of gambling activities that are played more than one a month; Gambling frequency - Past year gambling on a preferred gambling activity; PGSI - Past year gambling problems as assessed by the Problem Severity Index. 
Fig. 1 Mediation model of Gambling-related Cognitions Scale (GRCS) total scores, gambling frequency and gambling scope in 333 gamblers. Age, gender and first language were added as covariates. Sample items on the Chinese Belief in Luck Scale (CBLS) are included below the figure.

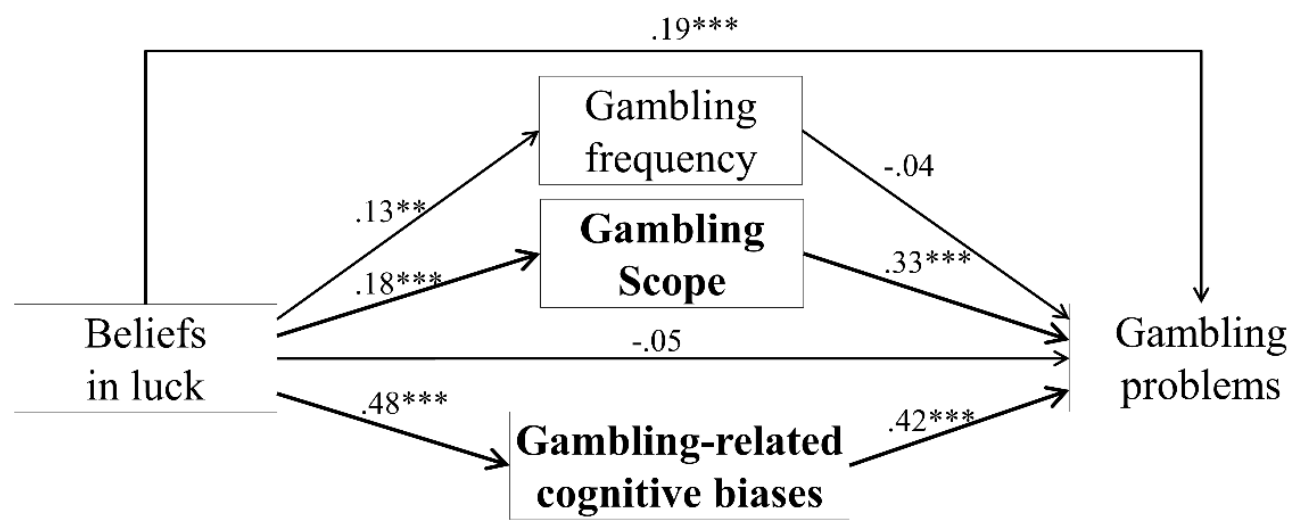

Beliefs in changing luck: "Carrying a lucky charm will bring good luck"

Beliefs in lucky wins: "Winning or losing depends on luck"

Beliefs in lucky numbers: "The number 6 represents a good omen"

Beliefs in lucky signs: "Your palm lines impact your future" 
Supplementary Materials 


\section{Factor structure the Chinese Beliefs in Luck Scale}

A Principal Component Analysis (PCA) of CBLS item scores was conducted using a (direct) oblique rotation. This method was justified by the adequate sample size (Kaiser-Meyer-Olkin statistic; KMO > .92) (23), and covariance amongst all items of the scale (individual item KMO > .85; Barlett's test of sphericity, $\chi 2>3481.63$, $\mathrm{p}<.001)$. Factors were extracted using eigenvalue scree plots and the overall model fit as measured by average extraction communalities.

A scree plot showed inflexions that would suggest either a 1 or 4 factor structure. The 4 -factor solution was chosen because it showed better average extraction communalities compared to the 1 -factor solution ( 0.84 as opposed to 0.62 ), and had fewer non-redundant residuals ( $21 \%$ as opposed to $72 \%$ ). The factor loadings of the 4-factor solution are shown in Table S1. The items with strongest loadings on the four component suggest that they measure beliefs in changing luck, lucky wins, lucky numbers, and lucky signs; all salient features of Chinese luck beliefs.

Table S1 Summary of exploratory factor analysis results for the Chinese Beliefs in Luck Scale (all participants; $N=489$ )

\begin{tabular}{|c|c|c|c|c|c|}
\hline & \multirow[t]{2}{*}{ Items } & \multicolumn{4}{|c|}{ Rotated Factor Loadings } \\
\hline & & $\begin{array}{c}\text { Beliefs in } \\
\text { changing } \\
\text { luck }\end{array}$ & $\begin{array}{c}\text { Beliefs in } \\
\text { lucky } \\
\text { wins }\end{array}$ & $\begin{array}{c}\text { Beliefs in } \\
\text { lucky } \\
\text { numbers }\end{array}$ & $\begin{array}{c}\text { Beliefs in } \\
\text { lucky } \\
\text { signs }\end{array}$ \\
\hline 6 & $\begin{array}{l}\text { Water fountains attract financial } \\
\text { prospects. }\end{array}$ & 0.53 & -0.05 & 0.11 & 0.41 \\
\hline 7 & $\begin{array}{l}\text { Special numbers, colours or clothing } \\
\text { increase chances of winning. }\end{array}$ & 0.76 & 0.01 & 0.08 & 0.12 \\
\hline 10 & Lucky days increase chances of winning. & $\mathbf{0 . 8 8}$ & 0.17 & -0.03 & -0.07 \\
\hline 11 & $\begin{array}{l}\text { Carrying a lucky charm will bring good } \\
\text { luck. }\end{array}$ & 0.82 & -0.02 & 0.14 & 0.00 \\
\hline 8 & Winning or losing depends on fate. & 0.15 & 0.74 & 0.06 & 0.10 \\
\hline 9 & Winning or losing depends on luck. & -0.03 & 0.96 & 0.00 & -0.02 \\
\hline 1 & The number 8 represents prosperity. & -0.01 & 0.06 & 0.94 & -0.03 \\
\hline 2 & $\begin{array}{l}\text { The number } 4 \text { is unlucky because it is } \\
\text { pronounced like death in Chinese. }\end{array}$ & 0.08 & -0.07 & 0.91 & -0.04 \\
\hline 3 & The number 6 represents a good omen. & -0.04 & 0.05 & 0.86 & 0.09 \\
\hline 4 & I will not let a mirror face my bed. & -0.10 & 0.10 & 0.09 & 0.90 \\
\hline 5 & Your palm lines impact your future. & 0.32 & -0.01 & -0.02 & $\mathbf{0 . 7 0}$ \\
\hline & Eigenvalues & 5.60 & 3.41 & 5.36 & 4.43 \\
\hline & $\alpha$ & .92 & .81 & .91 & .82 \\
\hline
\end{tabular}

Note: Factor loadings over .50 are in bold. Chrombach's $\alpha=.94$. 
Table S2 The Chinese Beliefs in Luck Scale (CBLS) and its instructions in Chinese script

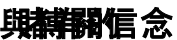

以下列出了些华人的普遍迷信思想。請圈選出您個人對每項原因的同意程度。

[1=強烈不同意, $2=$ 中度不同意, $3=$ 輕微不同意, $4=$ 沒意見, $5=$ 輕微同意, $6=$ 中度同意, $7=$ 強烈同意 $]$

1. 認為八是吉利的數字，因「八」與「發」音很接近

2.. 認為「死」音近「四」，因而對數字四有所禁忌

3.「六」代表六六大順或六六無窮

4. 我不會將房內的床正對鏡子

5. 您的掌紋影響您的未來

6. 喷水泉能招財

7. 特別的數字、顏色、物件或者衣著可以增加你贏的機會

8. 賭博的輸贏純粹是靠命或氣數

9. 賭博的輸贏純粹是靠運氣

10. 有些日子是賭博的幸運日

11. 佩戴吉祥小飾物將帶來好運

Fig. S1 Mediation model of GRCS subscale scores in 333 gamblers (separate mediation models were conducted for each subscale of the GRCS). Gambling frequency and gambling scope were added as mediating variables but not illustrated here. Age, gender, and first language were added as covariates.

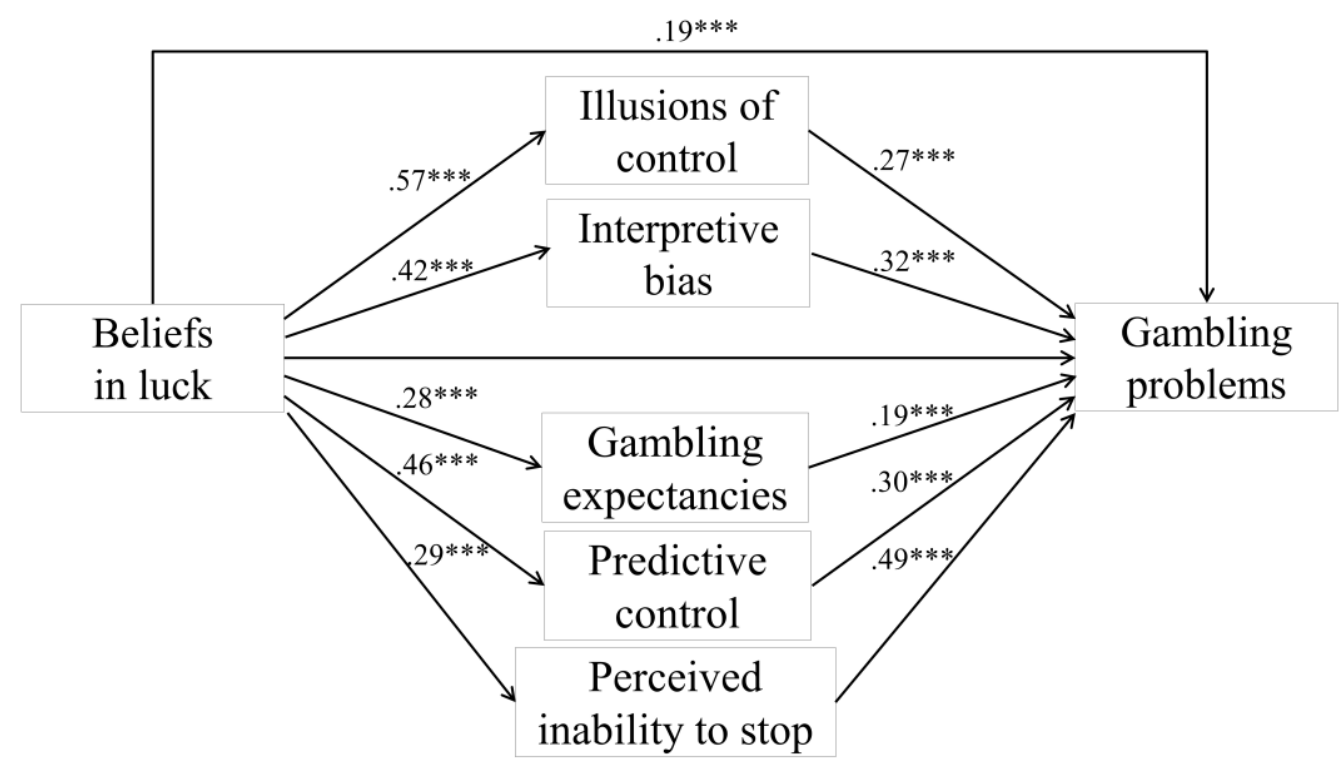

